\title{
Study on the Hourly Performance of A Solar Driven Ejector Refrigerant System
}

\author{
Zheng Huifan,Fan Xiaowei \\ Zhongyuan University of Technology
}

\author{
Zhang Lihe \\ Zhongyuan University of Technology
}

\begin{abstract}
An experimental setup about solar ejector refrigeration is designed and built using HFC134a as working fluid in this paper. Based on Zhengzhou meteorological parameters, the hourly coefficient of performance(COP), energy efficient ratio(EER), cooling capacity and other parameter about the ejector refrigeration system have been researched with the solar radiation changed, The experimental data show that the hourly COP and EER of the system change constantly, and it has been influenced by the solar radiation, the ambient temperature, generator temperature, and condenser temperature et al., and the cooling capacity, heat transfer capacity about the exchanger, and generator temperature appear rise and fall in the research range. The average daily COP is 0.18 at the July 26 , the average EER can up to 3.5.
\end{abstract}

Keywords-Solar ejector refrigeration;Hourly performance; Solar radiation

\section{INTRODUCTION}

In the utilization of solar energy technology, solar ejector refrigeration for its simple structure, fewer components attracts attention in recent years. Solar ejector refrigeration system performance have been experimental studied by many researchers, such as: Yapici[1] et al have experimental studied the characteristics about the solar ejector refrigeration using R11 as the refrigerant in 2007. Mani[2] et al have experimented on the performance of ejector refrigeration system with working refrigerant ammonia, HFC134a, HFC152a and HFC290. Eamesa[3] had studied the relevant system performance about the solar ejector refrigerant when the R245 is the working fluid in 2007. Rafet[4] had researched the performance about the R123 ejector refrigerant system experimentally in 2008. In the literature[5], the performance of the solar-driven ejector refrigeration system with water as the refrigerant has been studied in 2009, and the research evaporation temperature between $5 \sim 10^{\circ} \mathrm{C}$, the generator temperature between $85 \sim 140^{\circ} \mathrm{C}$, the condensing temperature varied between $15 \sim 35^{\circ} \mathrm{C}$. In addition, the performance of an ejector cooling system driven by solar energy has been studied by Shen Sheng-qiang, Zhang Yu-fengthe et al[6 7].

The performance of an ejector refrigeration system driven by solar energy is directly dependent on solar radiation and ambient temperature in day-time. Therefore, based on the climate data of zhengzhou area[8], select HFC134a as refrigerants, an experimental set up has been established, and the performance of ejector refrigerant has been researched under the typical meteorological parameters.

\section{DESCRIPTION OF THE SOLAR EJECTOR REFRIGERANT SYSTEM}

The schematic diagram of the experimental setup of the ejector refrigeration driven by solar refrigerant system is shown in figure 1 . The system consists of three parts that are solar ejector refrigeration system, water system and data acquisition and measurement system. Solar ejector refrigeration system consists of one generator, gas-liquid separator, ejector, evaporator, condenser, liquid receiver, expansion valve, refrigerant pump and other components. The generator, evaporator and condenser are tube-in-tube heat exchanger. With the help of a simulator using electrical energy, high-pressure primary vapor is generated in the generator by adjusting the input power of electric heater to simulate solar radiation under various conditions. A gasliquid separator was linked between the generator and the ejector, so that it can ensure that the steam state into the ejector is superheated In addition, for observing the refrigerant state whether can meet the design and operation requirements or not. Three sight glasses are be placed in the inlet of evaporator, ejector and the jet pump respectively. Water system consists of cooling water system and solar hot water system, which are all including water pump, valve, piping, and constant temperature water tank composition. In order to reduce the heat transfer loss, the insulation material is set the outside of water pipe and heated water tank.

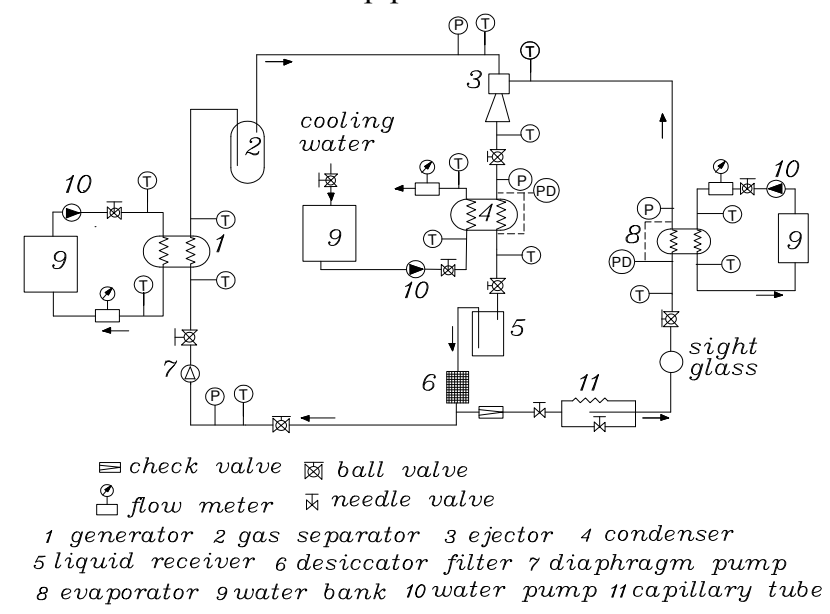

Figure 1. Schematic diagram of experimental setup for the ejector refrigeration system

During testing, the measured parameters include temperature, pressure, flow and power. Pt100 sensors are installed at appropriate locations for temperature 
measurement, and its accuracy can up to $\pm 0.2^{\circ} \mathrm{C}$. Flow meters are used to measure the flow rate of chilled water from the evaporator and cooling water from the condenser and hot water from the generator, and the flow meters can output 4-20 mA standard current signal, and their accuracy is up to $\pm 0.5 \%$, The pressures of the primary and entrained flows and the back pressure at the condenser are measured using Bourdon-tube gauges, and the sensor can output 4-20 $\mathrm{mA}$ standard current signals, and the measurement accuracy of $\pm 0.25 \%$; All instruments and devices used for data acquisition are calibrated, and all readings are recorded automatically and monitored by an Agilent 34970A data acquisition system. The system is set to the some desired operating condition.

Based on gas dynamics theory, designs the ejector, and the dynamic properties of refrigerant can help to refprop7.0 software.

Test procedure:

- Open tank heating electric heating equipment to heat water.

- Turn on chilled water pumps and cooling pumps, and adjust water flow rate and temperature to the designed condition.

- When water temperature meets the requirements of solar ejector refrigerant system, open the hot water pump.

- When the generator outlet refrigerant vapor temperature and pressure meets the requirements, start working refrigerant pump, then open the valve between the generator and the ejector, and the refrigerant vapor will flow into the ejector.

- Adjust throttle valve and all the heating water tank point of the system to meet the requirements in all states.

- Until system is stable, record the parameters of each measuring point though the data acquisition and the record time no less than 20 minutes.

\section{DATE REDUCTION}

The performance coefficient of an ejector refrigeration system is calculated by using the following formula:

$$
C O P=\frac{Q_{e}}{Q_{g}+W_{r}}
$$

Where, $Q_{e}$ is cooling capacity, $\mathrm{kW}$.

$Q_{g}$ is the heat transfer of generator, $\mathrm{kW}$.

$W_{r}$ is refrigerant pump power, $\mathrm{kW}$.

The pump power was neglected as it is very low with respect to Qg. The performance coefficient of the system is can be calculated from:

$$
C O P=\frac{Q_{e}}{Q_{g}}
$$

Cooling capacity is calculated as:

$Q_{e}=C_{p} \cdot m_{e w} \cdot\left(T_{\text {win }}-T_{\text {wout }}\right)_{e}$

Where, $C_{p}$ is specific heat, $\mathrm{J} /\left(\mathrm{kg} \cdot{ }^{\circ} \mathrm{C}\right)$. $m_{e w}$ is chilled water flow rate, $\mathrm{m} 3 / \mathrm{s}$.

$T_{\text {win }}$ is chilled water inlet-temperature of the evaporator, ${ }^{\circ} \mathrm{C}$.

$T_{\text {wout }}$ is chilled water outlet-temperature of the evaporator, ${ }^{\circ} \mathrm{C}$.

Generator heating capacity is calculated as:

$Q_{g}=C_{p} \cdot m_{g w} \cdot\left(T_{\text {win }}-T_{\text {wout }}\right)_{g}$

Where, ${ }^{m_{g w}}$ is water flow rate of the generator, $\mathrm{m} 3 / \mathrm{s}$.

$T_{\text {win }}$ is inlet- temperature of generator, ${ }^{\circ} \mathrm{C}$.

$T_{\text {wout }}$ is outlet-temperature of generator, ${ }^{\circ} \mathrm{C}$.

In the solar ejector refrigeration cycle, the solar heat accessed is free, so, EER is used to analyze the primary energy consumption, the system EER is defined as:

$$
E E R=\frac{Q_{e}}{W_{r}}
$$

\section{REsults AND Discussion}

According to the meteorological data of Zhengzhou area, chose the maximum solar radiation as a typical day[8]. The operation hourly characteristics of solar ejector refrigeration system have been experimental studied under typical meteorological conditions.

Figure 2 4 show hourly performance about solar ejector refrigeration system on 26th, July.

Figure 2 shows the hourly change of solar radiation $Q_{\mathrm{s}}$, the generator heat exchange $Q_{g}$ and the hourly ambient temperature $^{T_{w}}$ on 26th, July. It can be seen that $T_{w}$ increases first and then decrease, the maximum happens in 13:00, and the solar radiation is also increased firstly, then decreased, and its fluctuation range is less than the solar radiation, because the heat can be classified as lagging, or heat from the water tank reservoir decision. Between 10:00 and 13:00, the heat transfer of generator is less than the solar radiation, when time reach to 13:00, the solar radiation can reach to the maximum value, then the heat transfer of generator is slightly larger than solar radiation. In addition, when time is 9:00, the reason of the heat transfer of generator is greater than the solar radiation is mainly due to solar radiation stored before 9:00 am. And that some of the heat stored by the water first, when the system runs, those heat stored will be released, so the exchanger heat of generator is greater than the solar radiation heat transfer.

Figure 3 shows the hourly change of condensing temperature, COP, generator temperature on 26th, July. It can be seen from the figure that the generator temperature first decreases, then increased with time, and the COP is rising between 9:00 to 12:00 when 12:00 hour reach the first maximum, and the maximum is about 0.19 ; then, It decreasing, and when reach 13:00 time around, COP reaches its lowest point and the generator temperature and condensing temperature reach the maximum at the same time. The phenomenon can be explained by the temperature 
variation, at 13:00 time, with the solar radiation decreases, the temperature is also decreasing, and the COP has reached the second peak between 15:00 to 16:00 at the same time.

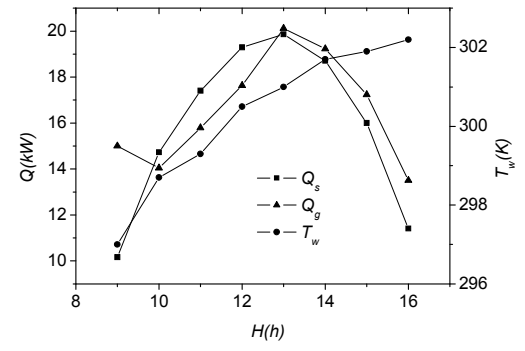

Figure 2. Hourly variation of $Q_{s}, Q_{g}$ and $T_{w}$ on 26th, July (Te=288K)

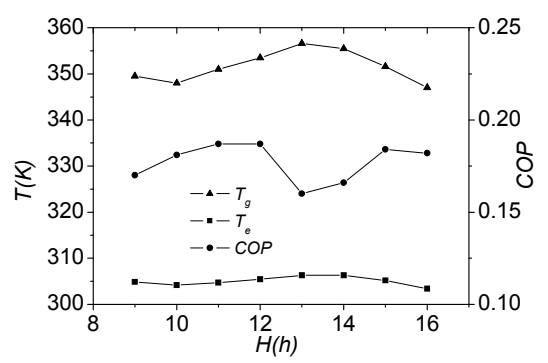

Figure 3. Hourly variation of $T_{g} 、 T_{c}$ and COP on 26th, July (Te=288K)

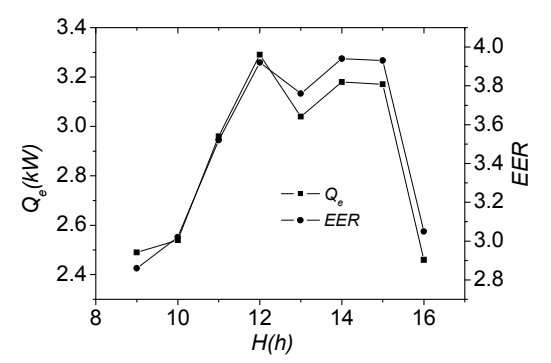

Figure 4. Hourly variation of cooling load $Q_{e}$ and EER on 26th, July $(\mathrm{Te}=288 \mathrm{~K})$

Figure 4 shows the hourly variation of cooling load, and

EER in 26th, July. As shown in Figure 4, the average $Q_{e}$ can reach to $2.9 \mathrm{~kW}$, and it is found that the average EER of the typical meteorological day can reach 3.5. In addition, the cooling capacity fluctuates between $2.4 \mathrm{~kW}$ and $3.3 \mathrm{~kW}$ when time varied among 9:00 and 16:00 on 26th, July, and the EER fluctuates between $2.86 \mathrm{~kW}$ and $3.94 \mathrm{~kW}$, which also suggests that solar ejector refrigeration system for airconditioning system has obvious advantages, and also feasible.

From the above analysis, when the solar ejector refrigeration system works, not the greater of the solar radiation, the greater of the cooling capacity, it is not the outdoor temperature is lower and the greater of the cooling capacity of the system.

The final system parameters such as COP and EER changes are influenced by the outdoor temperature, solar radiation, the system generator temperature and condenser condition and other parameters, such as: solar radiation directly effects the generator temperature, and outdoor temperature directly effects the condenser temperature, and every condensing temperature corresponding to one of the best generator temperature, while the generator temperature would effect the performance of solar ejector refrigeration, and through setting the appropriate strategy for controlling the water flow into the generator, and then can control the appropriate generator temperature and ensure the solar ejector refrigerant system runs under best condition whether it is in the state and sub-limit state or not, and this can improve the utilization of solar energy, enhance the system cooling capacity finally.

\section{SUMMARIES}

1)The generator temperature COP, and EER of solar ejector refrigeration system fluctuate with the time, and the generator temperature increases first, then decreases, and increases finally under the influence of solar radiation. The average COP is 0.18 , and the maximum COP is 0.19 at 26th July. In addition, the average EER can up to 3.5 , and the maximum EER is 3.94. These data suggest that solar ejector refrigeration system for air-conditioning system is the existence of advantages, but also feasible.

2)When solar ejector refrigeration system works, the cooling capacity of the system is not proportional to the solar radiation and outdoor temperature, and COP and EER will be influenced by the outdoor temperature, solar radiation, generator temperature and condenser temperature, and these propose a theoretical foundation for the control strategy about solar ejector refrigeration system.

\section{ACKNOWLEDGMENT}

The science and technology fund of henan province $(082102280010)$ and science and technology fund of the education department of henan province (2010A470007)

\section{REFERENCES}

[1] R. Yapıc1, C.C. Yetisen. Experimental study on ejector refrigeration system powered by low grade heat Energy[J]. Conversion and Management, 2007, 48:1560-1568.

[2] A. Selvaraju, A. Mani. Experimental investigation on R134a vapour ejector refrigeration system $[\mathrm{J}]$. International Journal of Refrigeration, 2006, 29: 1160-1166.

[3] W. Eamesa, Ali E. Ablwaifa b, Volodymyr Petrenkoc. Results of an experimental study of an advanced jet-pump refrigerator operating with R245 faIan[J]. Applied Thermal Engineering, 2007, 27: 28332840 .

[4] Rafet Yapic1. Experimental investigation of performance of vapor ejector refrigeration system using refrigerant R123[J]. Energy Conversion and Management, 2008, 49: 953-961.

[5] A.J. Meyer, T.M. Harms, R.T. Dobson 1. Steam jet ejector cooling powered by waste or solar heat[J]. Renewable Energy, 2009, 34: 297306 .

[6] Zhang Bo, Shen Shenqiang. Experimental study on performance of solar ejector refrigeration system [J]. Journa 1 of Therma 1 Science and Technology, 2006, 5(1): 59-63.

[7] Tianqi. Research about solar power united ejector-comperssion refrigerant system [D]. Tianjin university, 2005. 